\title{
PROPRIEDADES FÍSICAS, MECÂNICAS E TÉRMICAS DE TELHAS DE CONCRETO FABRICADAS COM ADIÇÃO DE DIFERENTES MATERIAIS ISOLANTES
}

\author{
Flávio Alves Damasceno¹, Otávio Assunção Peito Macedo², Jofran Luiz de Oliveira ${ }^{3}$, Carlos Eduardo Alves \\ Oliveira $^{4}$, Leidimar Freire Brandão ${ }^{5}$
}

\begin{abstract}
RESUMO
Objetivou-se, com a condução do presente trabalho, avaliar o efeito do uso de diferentes tipos e composições de materiais com características isolantes na confecção de telhas de concreto, com o propósito de melhorar suas propriedades físicas, mecânicas e térmicas. Os materiais isolantes usados foram: vermiculita em proporções de 5\% (TAV5) e 10\% (TAV10), poliestireno em proporções de 5\% (TAI5) e aditivo incorporador de ar em proporções de 5\% (TAA5). Testes foram realizados para determinação das propriedades físicas (dimensões, absorção de água e permeabilidade), mecânicas (resistência à ruptura por flexão) e térmicas das telhas de concreto. As propriedades físicas, mecânicas e térmicas das diferentes telhas foram comparadas às determinadas na telha testemunha (TAN), preparada com concreto normal, e avaliadas com base nos critérios mínimos estabelecidos pela NBR 13.858:2 (ABNT, 2009). Com base nos resultados das propriedades físicas, verificou-se que todos os tratamentos testados atenderam aos requisitos exigidos pela norma pertinente no país. No que se refere à propriedades mecânicas, nas diferentes telhas a carga de ruptura à flexão foi inferior ao mínimo recomendado. A incorporação de materiais com características isolantes em telhas de concreto apresentou boa eficiência na redução da temperatura da face interna das telhas.
\end{abstract}

Palavras-chave: telhado, material de construção, transferência de calor, construções rurais.

\section{ABSTRACT}

\section{PHYSICAL, MECHANICAL AND THERMAL PROPERTIES OF CONCRETE ROOF TILES MADE WITH ADDITION OF DIFFERENT INSULATING MATERIALS}

The objective of the present study was to evaluate the effect of using different types and compositions of materials with insulating characteristics in the production of concrete tiles, in order to improve the physical, mechanical and thermal characteristics of the tiles. The insulating materials used were vermiculite in proportions of 5\% (TAV5) and $10 \%$ (TAV10), polystyrene in the proportion of 5\% (TAI5 )and additive incorporated with air in proportions of 5\% (TAA5). Tests were conducted to determine the physical properties (dimensions, water absorption and permeability), mechanical (flexural strength at break) of thermal and concrete tiles. The physical, mechanical and thermal of different tiles were compared to data obtained from the reference tile (TAN) and evaluated based on the minimal criteria established by the NBR 13.858:2 (ABNT, 2009). Based on the results of the physical properties, it was found that all treatments met the requirements of the relevant standard in the country. As regards the mechanical properties, various tiles in the flexural tensile strength was lower than the recommended minimum. The incorporation of materials with insulating characteristics of concrete tiles showed good efficiency in reducing the temperature of the tiles.

Keywords: roof tiles, building material, heat transfer, rural buildings.

\section{Recebido para publicação em 11/12/2014. Aprovado em 19/08/2015.}

1 - Eng. Agrícola, Prof. Dr., Universidade Federal de Lavras (UFLA), Dep. de Engenharia, e-mail: flavio.damasceno@deg.ufla.br

2 - Eng. Agrícola, UFMT, Dep. de Engenharia Agrícola e Ambiental, E-mail: otavio@agricola.eng.br

3 - Eng. Agrícola, Prof. Doutor, UFMT, Dep. de Engenharia Agrícola e Ambiental, e-mail:jofranluiz@gmail.com

4 - Graduando em Eng. Agrícola, UFMT, Dep. de Engenharia Agrícola e Ambiental, E-mail: ceao.eaa@hotmail.com

5 - Eng. Civil, Mestre em Construção Metálica, E-mail: leidimarbrandao@yahoo.com.br

\section{REVENG} 406-417p. 


\section{INTRODUÇÃO}

As telhas de concreto são componentes utilizados para cobertura, com forma retangular e perfil geralmente ondulado, composto de cimento, agregado miúdo e água, podendo conter aditivos, fornecidos nas cores naturais ou coloridas, pela adição de pigmento à massa ou pela aplicação de uma camada superficial. Assim, quando comparadas com telhas de cerâmica simples, as telhas de concreto apresentam, aproximadamente,o mesmo peso, sendo resistentes e com formato diferenciado,além de apresentarem diferentes opções de cores (TÉGULA, 2005).

Atualmente, as telhas deconcreto sãoempregadas mundialmente, devido a sua praticidade, estética e durabilidade e, apesar do nome, é um artefato de cimento feito com concreto específico, constituído somente por aglomerante, agregado miúdo, aditivo químico e água (SAVASTANO JUNIOR; PIMENTEL, 2000; SAVASTANO JUNIOR et al., 1999).

De acordo com Valcarenghi e Piovesan (2011), Peixoto et al. (2010) e John e Tomas (1994), como vantagens, as telhas de concreto apresentam boa resistência mecânica, são duráveis e de fácil manuseio, oferecem opções de cores, são resistentes à ação intempérica, apresentam um conjunto de peças complementares para acabamento nas diversas partes do telhado e apresentam baixo índice de absorção de água. Por outro lado, destacam-se como desvantagens, o peso elevado, a alta porosidade, o que a torna suscetível ao rápido umedecimento $\mathrm{e}$, com isso, necessitando de limpeza anual.

Dada à importância da fabricação de telhas de concreto, a Associação Brasileira de Normas Técnicas (ABNT) desenvolveu normas que regulamentam o padrão de qualidade das telhas de concreto (VALCARENGHI; PIOVESAN, 2011).

Assim, o conhecimento de padrões de qualidade, em aspectos relacionados às propriedades físicas, mecânicas e térmicas das telhas de concreto, e a busca de novas alternativas para materiais são essenciais para reduzir os custos e ao mesmo tempo manter o equilíbrio dos elementos climáticos que afetam de maneira direta e indireta o desempenho térmico no interior dos galpões para criação animal.
O telhado influi no ambiente térmico interno de construções via material constituinte das telhas, da sua natureza superficial e da existência e eficiência de isolantes térmicos e forros. Assim, o tipo de material presente nas telhas determinará a quantidade de radiação nas instalações zootécnicas, contribuindo para a elevação da temperatura no seu interior. No caso dos aviários, soma-se o calor latente e sensível produzido por cada ave, aumentando a carga térmica radiante e, consequentemente, a temperatura do ar no interior da instalação (CONCEIÇÃO et al., 2008).

Diversas pesquisas têm sido conduzidas no sentido de se avaliar e comparar as telhas de concreto com outros tipos de telhas (SILVA; SILVA, 2012; ABREU et al., 2011; SAVASTANOJUNIOR; PIMENTEL, 2000; CONCEIÇÃO et al., 2008; SÁNCHEZ DE ROJAS et al., 2007; KAWABATA et al., 2005; PAKER et al., 2000; SAVASTANO JUNIOR et al., 1999). Devido à falta de difusão de conhecimento sobre as propriedades das telhas de concreto, o desenvolvimento de pesquisas se mostra importante para a literatura acadêmica, atribuindo novas informações para o avanço da tecnologia dos materiais de construção, visando a melhoria do conforto térmico no interior das instalações para produção animal.

Neste contexto, objetivou-se com a condução do presente trabalho, analisar as propriedades físicas, mecânicas e térmicas de telhas de concreto confeccionadas com diferentes tipos e composições de materiais, considerando-se os critérios mínimos estabelecidos pela NBR 13.858:2 (ABNT, 2009).

\section{MATERIAL E MÉTODOS}

Para realização deste estudo, confeccionou-se cerca de 300 telhas de concreto com diferentes tipos e composições de materiais, visando se promoverem alterações nas propriedades físicas, mecânicas e térmicas destas telhas.

As telhas foram confeccionadas na fábrica de telhas, situada no município de Rondonópolis e transportadas para o Laboratório de Materiais da Universidade Federal de Mato Grosso (UFMT), campus Rondonópolis-MT (latitude de $16^{\circ} 01^{\prime} \mathrm{S}$ de latitude, $49^{\circ} 48^{\prime} \mathrm{W}$ de longitude, $722 \mathrm{~m}$ de altitude e pressão atmosférica de $929 \mathrm{hPa}$ ), para posterior 
realizaçãodos ensaios, conforme recomendado pela NBR 13.858:2 (ABNT, 1997).

Neste estudo, os tratamentos foram assim constituídos: TAN - telha de concreto normal (testemunha); TAV5 - telha de concreto com 5\% de vermiculita; TAV10 - telha de concreto com $10 \%$ vermiculita; TAA5 - telha de concreto com aditivo incorporador de ar na proporção de 5\%; e TAI5 telha de concreto com $5 \%$ de poliestireno.

O processo de fabricação das telhas de concreto seguiu a metodologia empregada por Hans \& Schulz (1993) compreendido por: cálculo da quantidade de materiais, preparação da concreto, moldagem, processo de cura, desforma e estocagem.

Primeiramente, determinou-se as quantidades de materiais (vermiculita, poliestireno ou aditivo incorporador de ar) incorporadosao concreto para fabricação das telhas de cada tratamento. Assim, nos tratamentos com vermiculita (TAV5 e TAV10) e poliestireno (TAI5), determinou-se o volume médio ocupado pela areia fina e seca presente no concreto para confecção da telha. Neste caso, o traço utilizado foi de 1:3,5 (cimento e areia fina), considerando-se que a massa unitária da areia fina e seca é igual a 1,5 $\mathrm{kg} \mathrm{L}^{-1}$ (CARNEIRO et al., 1997; CABRAL et al., 2009), estimou-se o volume total ocupado pela areia $\left(\mathrm{V}_{\text {areia }}\right)$ por meio da equação 1:

$$
\mathrm{V}_{\text {areia }}=\frac{\mathrm{M}_{\text {areia }}}{\mathrm{MU}_{\text {areia }}}
$$

em que,

$\mathrm{M}_{\text {areia }}$ é a massa da areia, em kg; e

$\mathrm{M}_{\text {Uareia }}$ é a massa unitária da areia, em $\mathrm{kg} \mathrm{L}^{-1}$.

Com isso, o volume médio de $5 \%$ de areia fina, para cada $1 \mathrm{~kg}$ de cimento, foi de 0,1165 L. Deste modo, para confecção de 50 telhas de concreto, utilizou-se $50 \mathrm{~kg}$ de cimento, o volume médio ocupado por 5\% de areia fina foi de 5,82 L. Assim, o volume de areia foi substituído pelo volume de material com característica isolante (vermiculita e poliestireno) em cada tratamento.

No tratamento TAA5, utilizou-de um aditivo incorporador de ar, desenvolvido para uso em concretos em geral. A quantidade de aditivo utilizada no traço do concreto das telhas produzidas manteve-se dentro da faixa especificada pelo fabricante, ou seja, para cada $100 \mathrm{~kg}$ de cimento, $40 \mathrm{~mL}$ de aditivo foram adicionados. Para a fabricação das telhas, a areia utilizada no concreto foi colocada numa peneira automática de $3,5 \mathrm{~mm}$ para a retirada de impurezas (Figura 1a).

Após peneirada, a areia foi depositada numa tremonha, um reservatório localizado no início da esteira de agregados, permitindo o armazenamento da areia peneirada e a dosagem da quantidade necessária, em volume (L), de agregado por traço.

No preparo do concreto, os materiais presentes nas telhas (aglomerante, areia fina e água) foram adicionados em um misturador, com o objetivo de uniformizar e homogeneizar o concreto. $\mathrm{O}$ concreto foi misturado durante 4 minutos (Figura 1b). Depois de misturado, o concreto seguiu para a uma caixa alimentadora da máquina por meio de uma esteira (Figura 1c), onde a extrusora fez a moldagem das telhas sob a pressão gerada no processo de extrusão. A extrusora era constituída por várias partes, tais como: a) garfo compactador, que empurrava o concreto para debaixo do rolo; b) rolo alisador, responsável pelo pré-acabamento no formato da superfície das telhas; c) sliper, que fez o acabamento superficial final; e d) réguas laterais, que fizeram o acabamento lateral da peça determinando a largura das telhas. $\mathrm{O}$ processo de fabricação das telhas de concreto pode ser observado na Figura 1d.

O concreto misturado foi transportado do misturador até a máquina extrusora, fôrmas de alumínio com os moldes das telhas foram responsáveis pelo formato inferior das telhas de concreto.

Logo após o processo de extrusão, as telhas moldadas seguiram para as prateleirasonde ficavam numa sala fechada para realizar o processo de cura das telhas durante 24 horas. Nesta etapa, as telhas passaram por uma esteira, onde foi feita a aplicação de uma resina desmoldante.

A última etapa do processo de fabricação consistiu na desmoldagem das telhas. Essa etapa foi responsável pela remoção das telhas de concreto das suas respectivas fôrmas. Por fim, as telhas passaram por um processo de cura de 7 dias.

As propriedades físicas, dimensões, massa, 


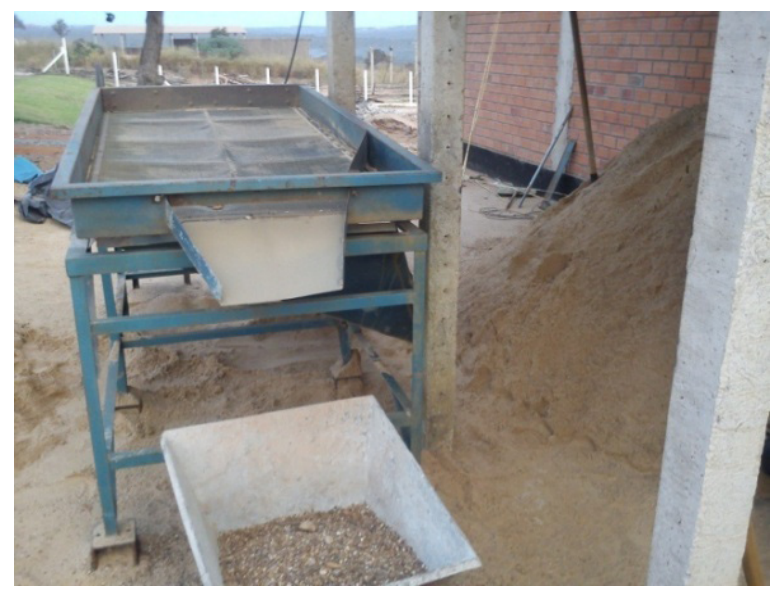

(a)

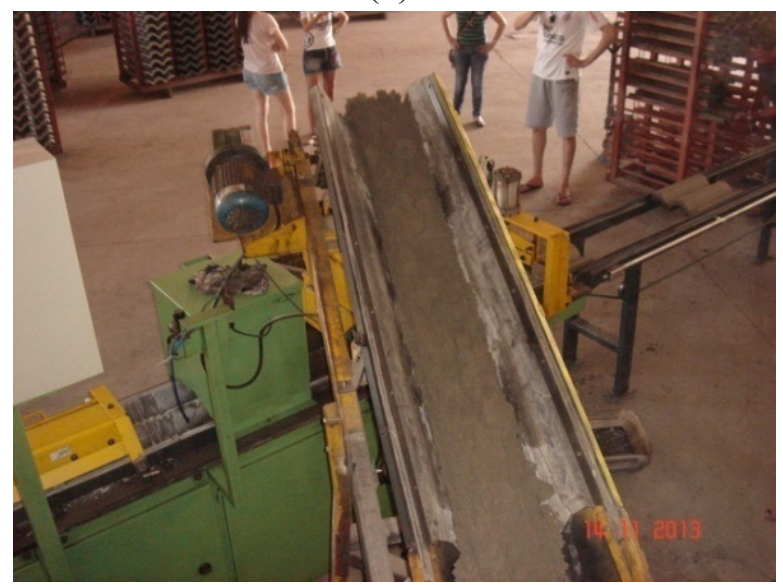

(c)

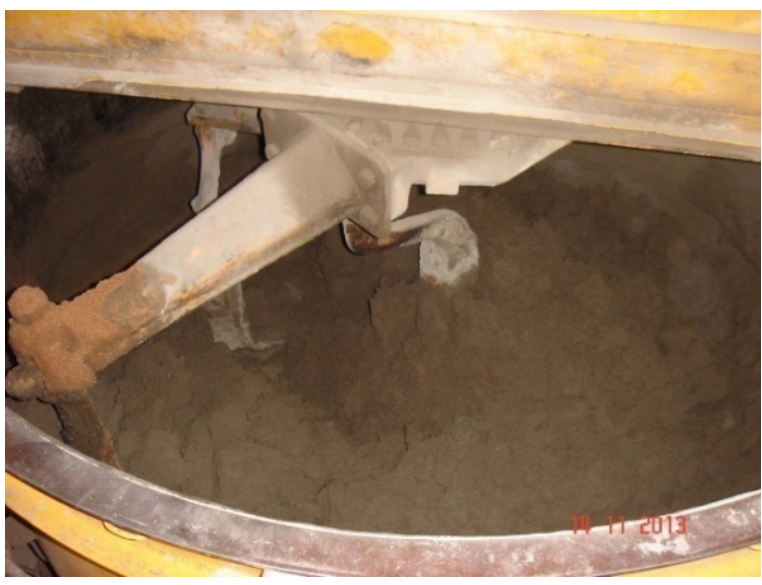

(b)

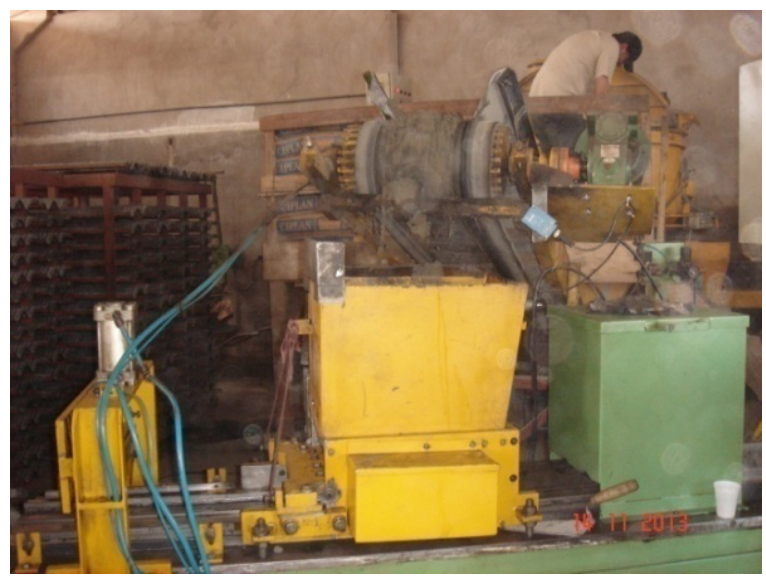

(d)

Figura 1. Figura 1. Processo de fabricação das telhas de concreto: a) peneira; b) misturador; c) esteira; e d) extrusora.

permeabilidade e absorção de água, foram determinadas de acordo com a norma NBR 13.8522 (1997), para telhas de concreto.

$\mathrm{O}$ ensaio de permeabilidade consistiu em submeter a telha a uma coluna d'água de 250 mm durante 24 horas, com observação visual da presença de água na sua face oposta. Para fixação e vedação dos tubos de PVC, utilizou-se silicone na base dos tubos.

Para determinação da absorção de água, as telhas foram imersas numa caixa d'água de $500 \mathrm{~L}$ por 24 horas, posteriormente, deixou-se escorrer o excesso de água por 1 minuto. Em seguida, as telhas foram colocadas na estufa a $105^{\circ} \mathrm{C}$, por 24 horas. Com uma balança digital, com resolução de $0,01 \mathrm{~kg}$, mediu-se a massa das telhas antes e após a secagem. Determinou-se a absorção da água pela telha $\left(\mathrm{A}_{\mathrm{bs}}\right.$, em \%), conforme descrito pela equação 2 .
$A_{b s}=\frac{M_{\text {sat }}-M_{s}}{M_{\text {sat }}} \cdot 100$

em que,

$\mathrm{M}_{\text {sat }}$ é a massa saturada $(\mathrm{kg})$; e

$\mathrm{M}_{\mathrm{s}}$ é a massa seca $(\mathrm{kg})$.

Para determinação das dimensões das telhas de concreto, cinco telhas de cada tratamento foram selecionadas aleatoriamente. A largura e comprimento foram medidas com auxílio de uma régua graduada de plástico transparente. As espessuras das telhas foram medidas com auxílio de um micrometro externo $(0-25 \mathrm{~mm})$.

Das propriedades mecânicas, foi realizado o teste de flexão, conforme ilustrado na Figura 2. 
Para tanto, utilizou-se uma máquina universal de ensaios (TIME-Shijin Group, modelo WDW-100E, com capacidade máxima de $100 \mathrm{kN}$ ). A máquina de ensaio permitiu o controle da velocidade de aplicação da carga, facilitando os ensaios. Neste estudo, as telhas foram previamente imersas em água por 24 horas. A finalização do ensaio ocorreu ao ser constatado a ruptura da telha. Neste teste, foi verificada a resistência à flexão das telhas aos 7 , 14, 21 e 28 dias de cura. Os procedimentos foram realizados obedecendo-se a NBR 13.852:2 (1997), aplicando-se uma carga centralizada, progressiva, não excedendo a velocidade de carregamento de $1,0 \pm 1,0 \mathrm{~mm} / \mathrm{min}$.

Para a avaliação das propriedades térmicas das telhas de concreto, construiu-se uma caixa de madeira com comprimento de $0,95 \mathrm{~m}$, largura de $0,35 \mathrm{~m}$, altura de $0,15 \mathrm{~m}$ e espessura de $0,02 \mathrm{~m}$. Cinco lâmpadas incandescentes (127 volts e 15 watts cada) foram instaladas em série e distribuídas uniformemente no fundo da caixa de madeira. Um controlador de tensão do tipo dimmer foi instalado para controlar a potência das lâmpadas, permitindo, assim, controlar a temperatura no interior da caixa.

Toda parte interna da caixa de madeira foi coberta com papel alumínio para refletir a radiação gerada pelas lâmpadas. Uma placa metálica, pintada em preto fosco, foi colocada acima das lâmpadas de modo a distribuir mais uniformemente o calor gerado pelas lâmpadas (Figura 3a).

Para cada tratamento testado, duas telhas de concreto foram colocadas sobre a caixa de madeira. Para evitar a fuga de calor, as frestas entre as telhas e a caixa foram fechadas por fita autoadesiva com membrana asfáltica impermeável.

Em cada telha foram colocados quatro sensores de temperatura (modelo TMC50-HD, precisão $\pm 0,2{ }^{\circ} \mathrm{C}$ ), sendo dois na parte superior e dois na parte interna da caixa, conectados a sensores/ registradores com 4 canais $\left(\right.$ Hobo ${ }^{\circledR}$, mod. U12-006,

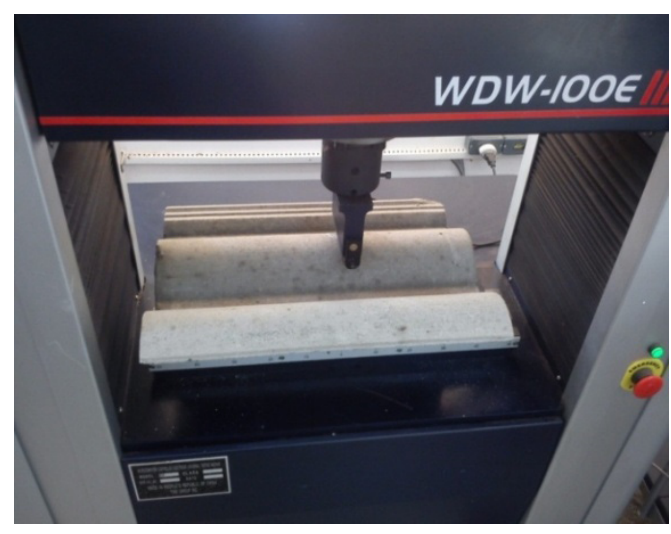

(a)

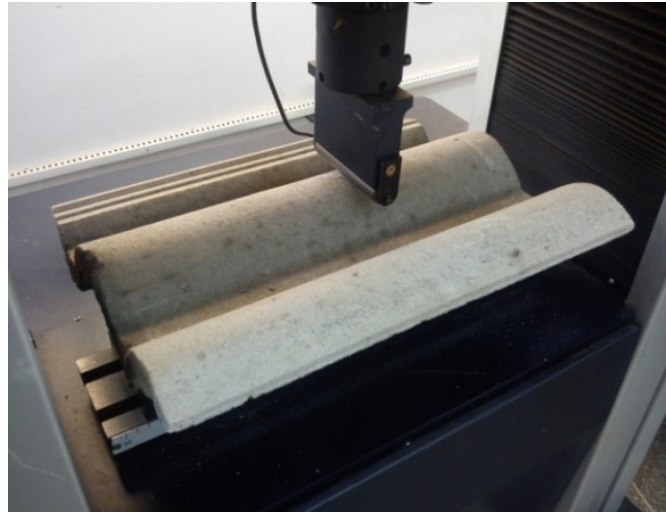

(b)

Figura 2. Teste de flexão de uma telha realizado na máquina universal de ensaios.

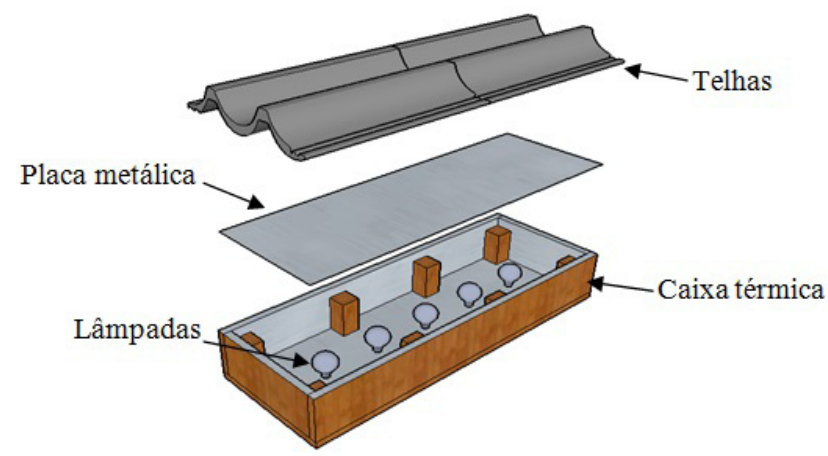

(a)

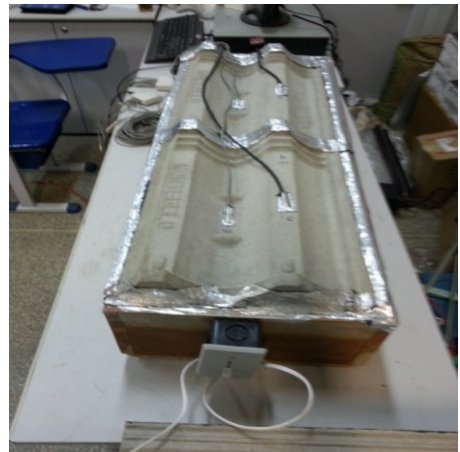

(b)

Figura 3. Avaliação das propriedades térmicas: a) desenho esquemático da caixa térmica e b) sensores de temperatura instalados sobre as telhas. 

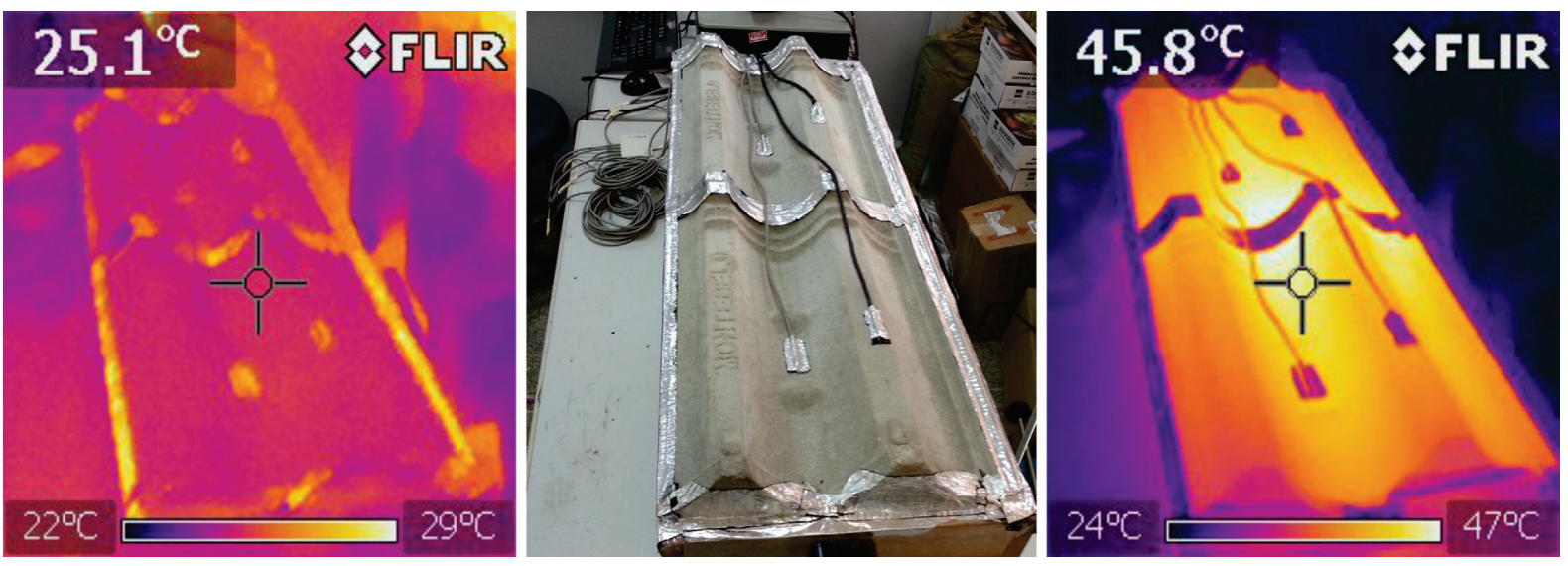

Figura 4. Imagem real e termográfica no início e final do período do experimento.

precisão $\pm 0,2^{\circ} \mathrm{C}$ ), conforme observado na Figura 3 b. Os sensores/resgistradores foram configurados para coletar dados de temperatura a cada 1 minuto, durante 24 horas. Um computador foi utilizado para configurar e monitorar a temperatura dentro e fora da caixa.

Para avaliação da temperatura superficial das telhas, imagens reais e termográficas da superfície inferior das telhas (Figura 4) foram coletadas a cada hora, por meio de uma câmera térmica $\mathrm{Flir}{ }^{\circledR}$ (modelo i5, resolução de 10.000 pixels e precisão $\left.\pm 2{ }^{\circ} \mathrm{C}\right)$.

As análises estatísticas dos dados das propriedades físicas, bem como as propriedades mecânicas e térmicas, foram realizadas utilizandose o programa computacional SISVAR, desenvolvido pela Universidade Federal de Lavras (FERREIRA, 2000), aplicando-se o teste ScottKnott, a 5\% de probabilidade.

\section{RESULTADOS E DISCUSSÃO}

As diferentes telhas submetidas ao ensaio para verificação da permeabilidade não apresentaram formação de gotas em sua face inferior, nem aparecimento de manchas decorrentes da presença de água, conforme o recomendado pela NBR 13.852:2 (1997), onde a telha não deve apresentar vazamentos ou formação de gotas em sua face inferior, sendo tolerado apenas o aparecimento de manchas decorrentes da presença de água.

Na Figura 5, têm-se os valores médios de água absorvida em cada tipo de telha avaliada. Não houve diferença significativa em relação à água absorvida dentre os tratamentos testados $(\mathrm{p}>0,05$; ScottKnott). Assim, observa-se que todos os tratamentos testados atenderam às exigências recomendadas pela NBR 13.852:2 (1997) referentes à absorção de água, que deve ser no máximo de $10 \%$. Valores semelhantes foram encontrados por Valcarenghi e Piovesan (2011), ao avaliar diferentes telhas de concreto com diferentes cores e modelos. Neste estudo, as telhas de concreto naturais (sem pigmentos) apresentaram menores valores de absorção de água.

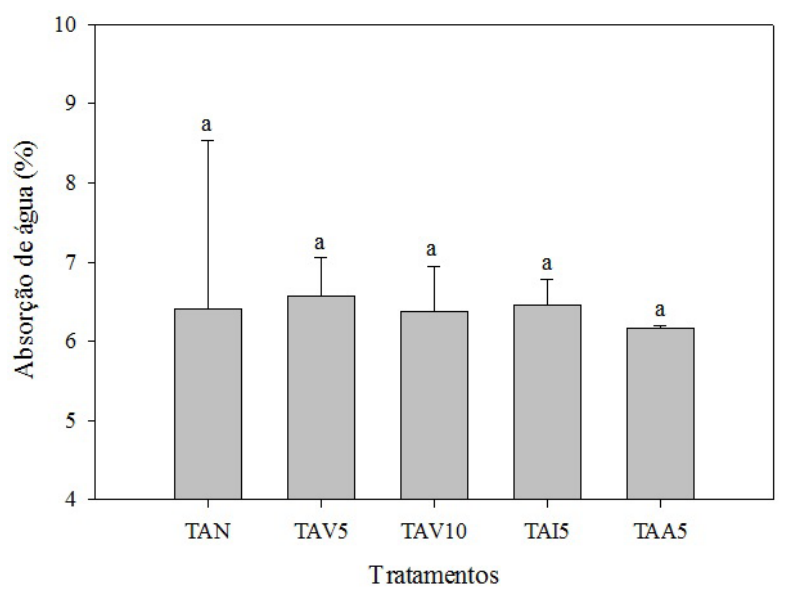

Figura 5. Valores médios e desvios-padrão da porcentagem de absorção de água pelas telhas de concreto para os diversos tratamentos testados. Médias seguidas da mesma letra, não diferem entre si pelo teste de Scott-Knott, a 5\% de probabilidade. 
$\mathrm{Na}$ Figura 6, têm-se os valores médios e os desvios-padrões referentes à largura das telhas de concreto para os diversos tratamentos testados e período avaliado. Não foi observada diferença estatística entre as variáveis relacionadas às larguras médias para os diferentes tipos de materiais isolantes testados e para o período avaliado ( $p>0,05$; ScottKnott). A largura média dos tratamentos testados variou entre 332,1 a 332,6 mm. Estes valores estão ligeiramente acima da largura máxima recomendada pela NBR 13.858-2 (1997) que é de $330 \mathrm{~mm}$. A substituição do cimento pelos materiais isolantes, provavelmente alterou asdimensões das telhas de concreto no processo de cura.
$\mathrm{Na}$ Figura 7, estão apresentados os valores médios para os comprimentos médios associados a cada tratamento e ao período avaliado. Pode-se observar na Figura 7a que o comprimento médio do tratamento TAN foi estatisticamente maior ( $\mathrm{p}<0,05$; Scott-Knott). Os valores médios do comprimento nos dias 7 e 14 foram estatisticamente maiores ( $p<0,05$; Scott-Knott). O comprimento dos tratamentos estudados apresentou valor próximo ao limite recomendado pela NBR 13858:2 (1997) que é de $420 \mathrm{~mm}$. Valcarenghi e Piovesan (2011) encontraram valores semelhantes em telhas de concreto com diferentes cores e modelos.

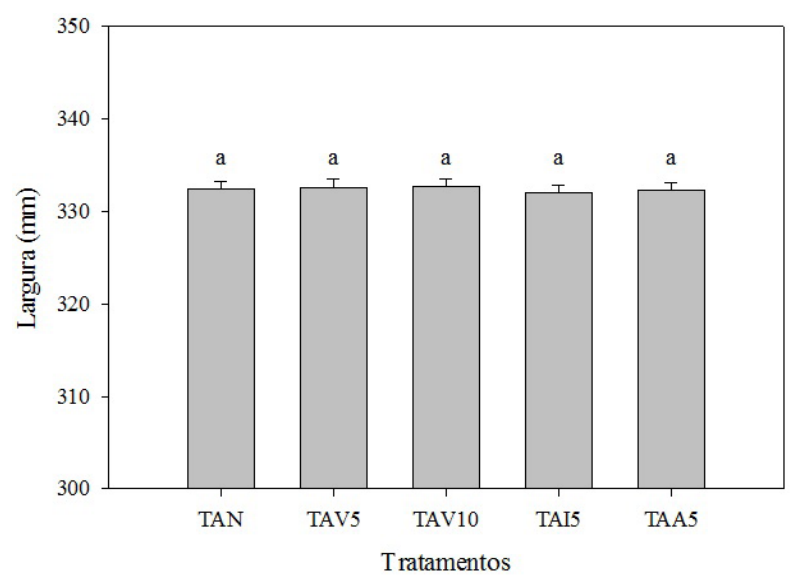

Limite recomendado pela NBR 13.858:2 (1997)

(a)

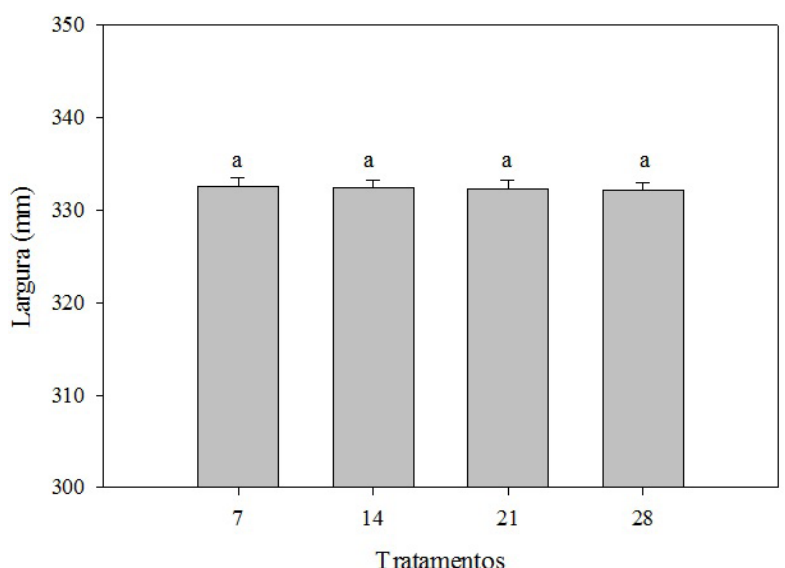

(b)

Figura 6. Valores médios e desvios-padrões da largura das telhas de concreto para: a) os diversos tratamentos testados e b) período de cura. Médias seguidas da mesma letra, não diferem entre si pelo teste de Scott-Knott, a 5\% de probabilidade.

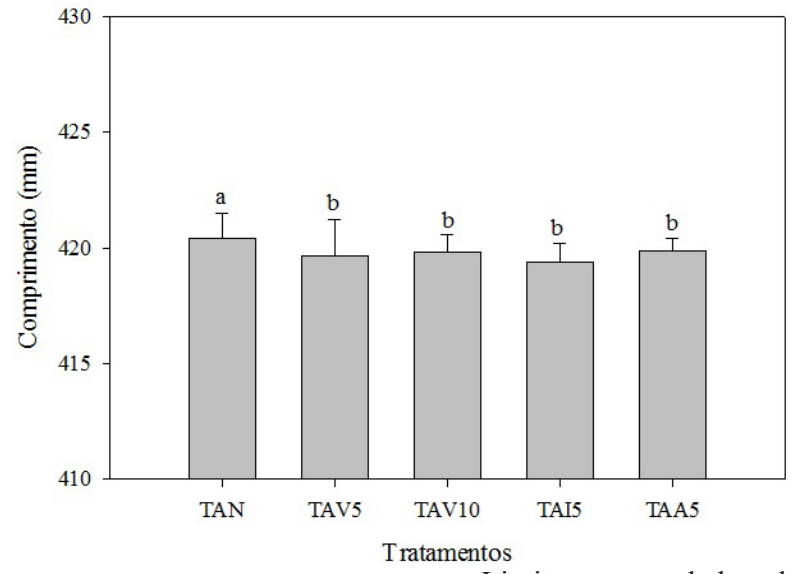

(a)

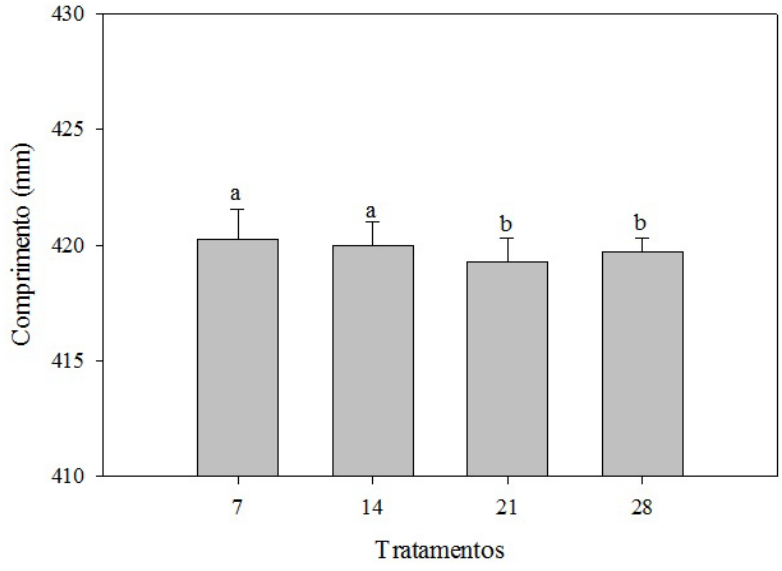

(b)

Figura 7. Valores médios e desvios-padrões do comprimento das telhas de concreto para: a) os diversos tratamentos testados e b) período de cura. Médias seguidas da mesma letra, não diferem entre si pelo teste de Scott-Knott, a 5\% de probabilidade.

\section{REVENG}

ENGENHARIA NA AGRICULTURA, VIÇOSA - MG, V.23 N.5, SETEMBRO / OUTUBRO 2015 

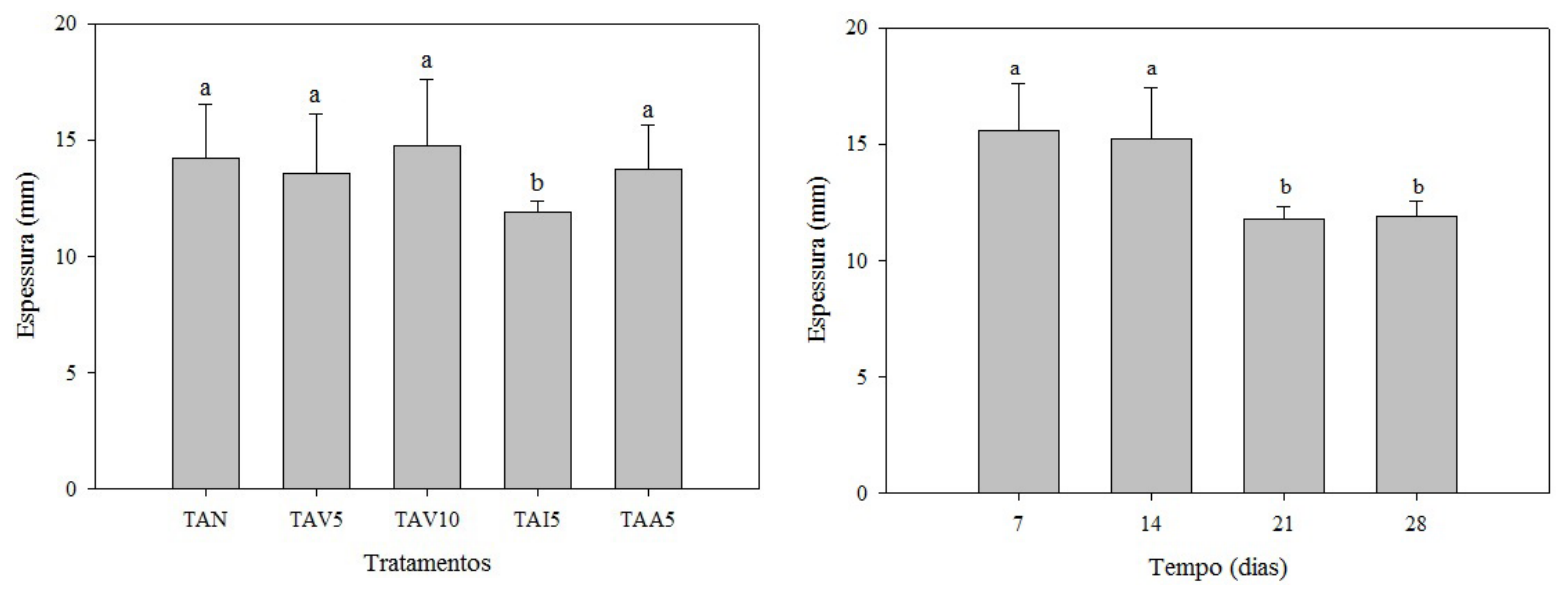

(a)

(b)

Figura 8. Valores médios e desvios-padrão da espessura das telhas de concreto para: a) os diversos tratamentos testados e b) período de cura. Médias seguidas da mesma letra, não diferem entre si pelo teste de Scott-Knott, a 5\% de probabilidade.

Na Figura 8, apresentam-se os valores médios e desvios-padrões da espessura das telhas de concreto para os diversos tratamentos testados e período de cura avaliado. Existe pelo menos uma diferença significativa entre os tratamentos testados ( $\mathrm{p}<$ 0,05; Scott-Knott). Conforme pode ser visualizado na Figura 8a, o valor médio da espessura da telha é estatisticamente menor no tratamento TAI5 $(11,9 \mathrm{~mm})$ dentre os tratamentos testados, porém, todos os tratamentos ficaram de acordo com a NBR 13.858:2 (1997), que estabelece a espessura mínima de $10 \mathrm{~mm}$ para a telha de concreto.

No geral, os valores médios de espessura das telhas foram decrescentes para os dias avaliados, devido a retração do concreto durante este período (Figura 8b).

Pela Figura 9, verificou-se diferença significativa ( $p<0,05$; Scott-Knott) entre os valores das massas das telhas de concreto nos diferentes tipos de materiais isolantes. A massa do tratamento TAV10, TAI5 e TAN foram estatisticamente superiores às massas dos demais tratamentos testados. Os tratamentos TAV5 e TAA5 foram estatisticamente inferiores a todos os demais quanto às massas das telhas pelo teste Scott-Knott, em nível de 5\% de significância.

Segundo Térgula (2005), as telhas de concreto são mais pesadas que as telhas convencionais de cerâmica por serem maiores, cobrindo um metro quadrado com apenas 10,4 telhas, enquanto as telhas de cerâmicas por serem consideravelmente menores cobrem um metro quadrado com 27 peças do seu modelo mais usual. Com isto, observa-se uma enorme semelhança na massa total das peças sobre uma determinada cobertura.

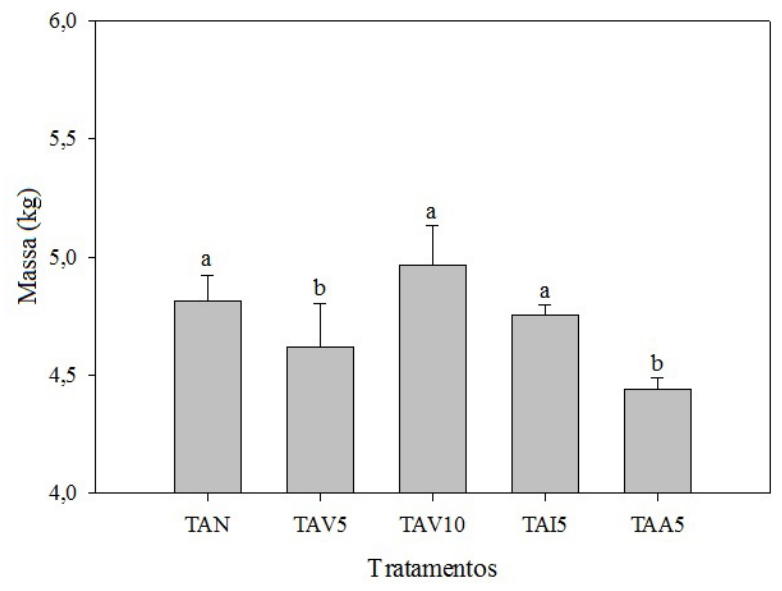

Figura 9. Valores médios e desvios-padrões da massa das telhas para os diversos tratamentos testados. Médias seguidas da mesma letra, não diferem entre si pelo teste de Scott-Knott, a 5\% de probabilidade.

Na Figura 10, ilustram-se as curvas de carga $\mathrm{x}$ deformação do ensaio de ruptura à flexão, para telhas de concreto produzidas com diferentes 


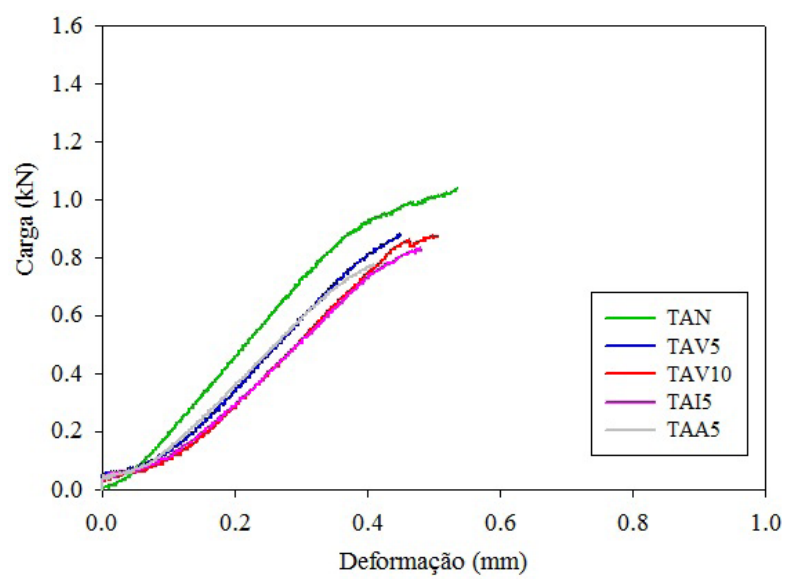

(a)

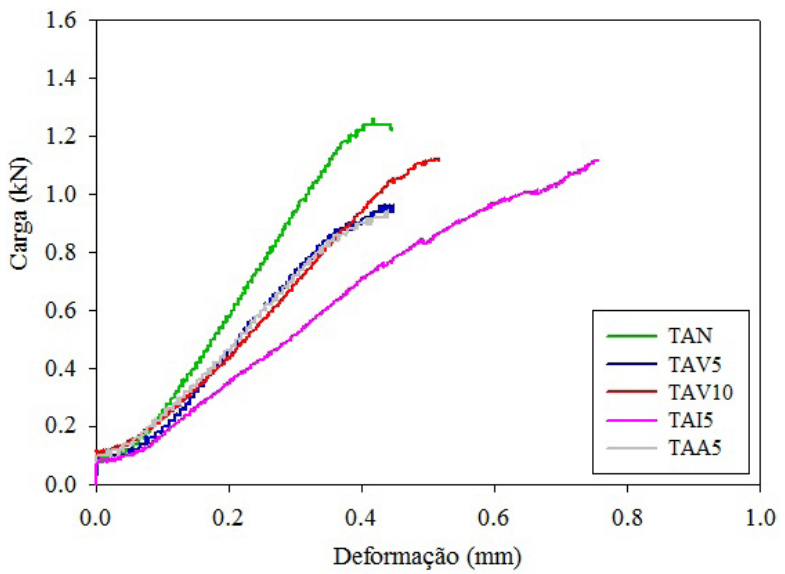

(c)

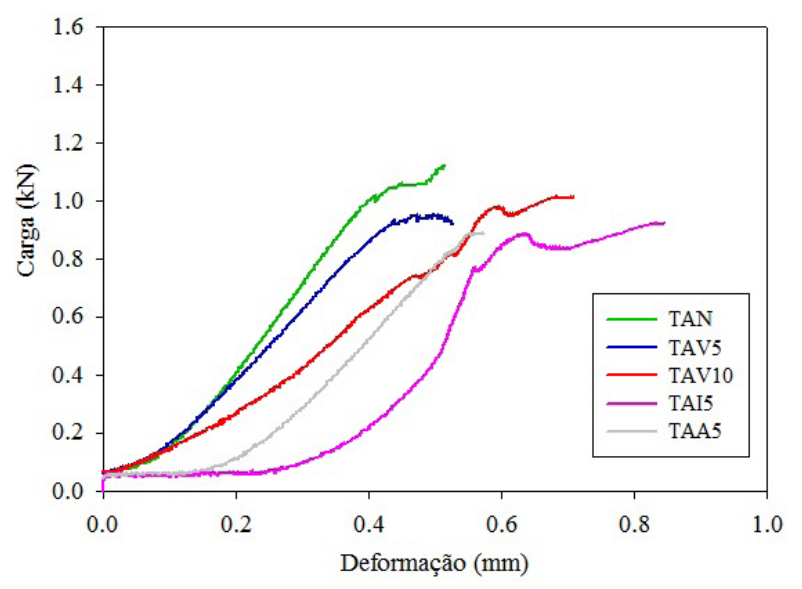

(b)

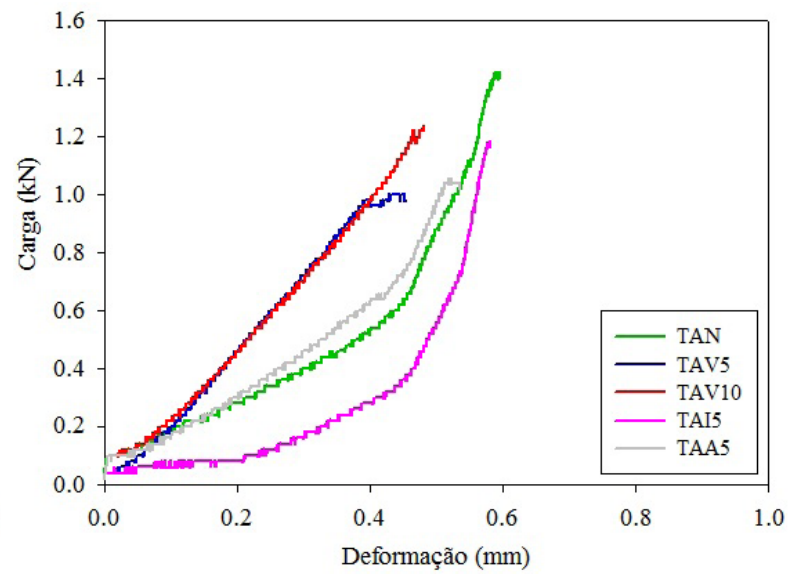

(d)

Figura 10. Curvas de comportamentos da flexão $x$ deformação durante os períodos de cura nos períodos: a) 7 dias, b) 14 dias, c) 21 dias e d) 28 dias.

materiais com características isolantes. Observase que o comportamento da resistência à flexão do tratamento TAV5 não sofreu alteração significativa no comportamento da curva quando comparado com os outros tratamentos testados. Nota-se que as curvas de comportamento carga $\mathrm{x}$ deformarção do tratamento TAI5, apresentam maior deformação, principalmente próximo ao início do ensaio, demonstrando que o poliestireno suporta a carga aplicada e evidencia a flexibilidade do material. Por outro lado, as curvas referentes ao tratamento TAA5 apresentaram picos acentuados que evidenciaram a característica de ruptura frágil do material, dada aà maior quantidade de poros presente nas telhas, resultando numa menor resistência ao esforço de flexão.

No Quadro 1 estão apresentadas as cargas máximas de rupturas à flexão e desvios-padrões durante os períodos avaliados nos diferentes tratamentos testados. Os resultados da carga máxima de ruptura à flexão, neste ensaio, foram comparados às especificações propostas pela NBR 13.852:2 (1997) para telhas de concreto produzidas pelo mesmo processo utilizado neste estudo. Deste modo, pode-se observar que o tratamento TAN suportou uma carga superior em comparação com os outros tratamentos testados. Entretanto, em todos os tratamentos a carga máxima de ruptura à flexão foi inferior ao mínimo recomendado pela NBR 13.852:2 (1997) de 2,50 kN (250 kgf). Observa-se que a incorporação de vermiculita, isopor e aditivo incorporador de ar na confecção das telhas pode prejudicar a resistência à flexão.

Os valores médios de cargas máximas de rupturas à flexão para os tratamentos TAN, TAV5, TAV10, TAI5 e TAA5 foram 1,21 $\pm 0,38 \mathrm{kN}$,

\section{REVENG 406-417p.


Quadro 1. Valores médios das cargas máximas de rupturas $(\mathrm{kN})$ à flexão e desvios-padrões durante o período avaliado.

\begin{tabular}{lccccccccccccccccc}
\hline Tempo & \multicolumn{3}{c}{ TAN } & \multicolumn{4}{c}{ TAV5 } & \multicolumn{2}{c}{ TAV10 } & \multicolumn{3}{c}{ TAI5 } & \multicolumn{3}{c}{ TAA5 } \\
\hline 7 dias & 1,04 & \pm & 0,34 & 0,88 & \pm & 0,28 & 0,88 & \pm & 0,29 & 0,83 & \pm & 0,26 & 0,78 & \pm & 0,24 \\
14 dias & 1,12 & \pm & 0,37 & 0,95 & \pm & 0,32 & 1,02 & \pm & 0,32 & 0,92 & \pm & 0,35 & 0,89 & \pm & 0,32 \\
21 dias & 1,26 & \pm & 0,40 & 0,96 & \pm & 0,34 & 1,12 & \pm & 0,34 & 1,12 & \pm & 0,33 & 0,94 & \pm & 0,28 \\
28 dias & 1,42 & \pm & 0,42 & 1,00 & \pm & 0,32 & 1,24 & \pm & 0,37 & 1,18 & \pm & 0,36 & 1,06 & \pm & 0,31 \\
\hline Média & 1,21 & \pm & 0,38 & 0,95 & \pm & 0,31 & 1,06 & \pm & 0,33 & 1,01 & \pm & 0,32 & 0,92 & \pm & 0,28 \\
\hline
\end{tabular}

$0,95 \pm 0,31 \mathrm{kN}, 1,06 \pm 0,33 \mathrm{kN}, 1.01 \pm 0,32 \mathrm{kN} \mathrm{e}$ $0,92 \pm 0,28 \mathrm{kN}$, respectivamente, conforme pode ser observado no Quadro 1. Assim, pela análise comparativa das cargas máximas de rupturas à flexão relativa aos tratamentos testados, entre $7 \mathrm{e}$ 28 dias de cura, observou-se que, os tratamentos TAV10 e TAI5 apresentaram um aumento de $29,4 \%$ e $29,5 \%$, respectivamente. Já o tratamento TAV5, para o mesmo período avaliado, apresentou aumento na resistência de carga máxima de ruptura à flexão de $12 \%$. Ademais, a resistência à flexão da telha de concreto deve obedecer a recomendação da norma vigente, pois muitas vezes estão sujeitas a esforços elevados, que ocorrem em situações de esforços proporcionados por pisadas sobre sua superfície do telhado em manutenção.

Silva e Silva (2012), ao avaliarem a influência da substituição de cimento e areia pelo rejeito de britagem das rochas para a produção de concretos, visando a produção de telhas de concreto, encontraram valores médios de força de tração de $285,4 \mathrm{kN}$.

Araújo et al. (2008), avaliando o comportamento mecânico e físico-químico das telhas ecológicas em comparação com as telhas convencionais (fibrocimento), encontraram os valores de cargas máximas de rupturas à flexão de $1,73 \mathrm{kN}$ e 0,48 $\mathrm{kN}$, respectivamente.

Na Figura 12 tem-se o gradiente de temperatura entre a superfície superior e inferior dos tratamentos testados ao longo de período avaliado. A interação tratamento $\mathrm{x}$ tempo foi significativa para todas as variáveis $(\mathrm{p}<0,05)$. Observa-se que o sentido do fluxo de calor foi positivo e ascendente, ou seja, da superfície superior para a inferior da telha, para todos os tratamentos avaliados, significando que as telhas na superfície superior aqueceram mais que na superfície inferior.

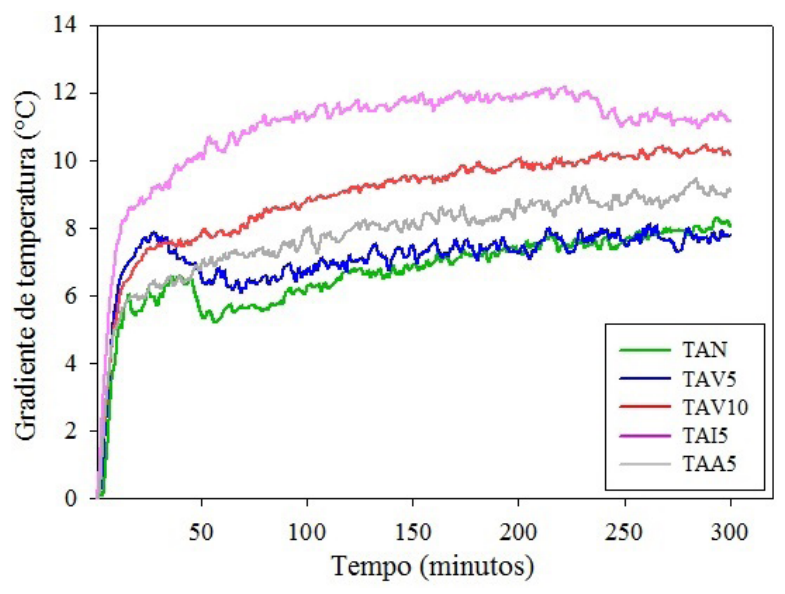

Figura 12. Gradiente médio entre a temperatura da superfície externa e interna dos tratamentos testados.

SegundoAbreu et al.(2011), a condição essencial para a transmissão de calor é que haja diferença de temperatura entre os meios, denominado gradiente de temperatura. Este gradiente indica o sentido do fluxo de calor. O sentido sempre vai ocorrer do maior para o menor valor. Se as temperaturas dos corpos forem iguais não haverá transferência de calor, nesse caso, os corpos estão em estado de equilíbrio térmico.

No interior das telhas, a transferência de calor ocorre por meio da condução realizada por contato entre as moléculas ou partículas das telhas. Para determinar a quantidade de calor transmitida 
é necessário conhecer o coeficiente térmico de condução (K) e a espessura do material (ABREU et al., 2011).

$\mathrm{Na}$ Figura 13, têm-se os valores médios e desvios-padrões do gradiente de temperatura para os tratamentos testados e, conforme pode ser observado, o gradiente térmico nos tratamentos com vermiculita, poliestireno e aditivo incorporador de ar, ou seja, materiais com maiores coeficientes térmicos de condução, foram estatisticamente maiores ( $\mathrm{p}<0,05$; Scott-Knott), quando comparado ao tratamento testemunha (TAN). Assim, é recomendada a incorporação de materiais com características isolantes em telhas de concreto, uma vez que a energia térmica da superfície externa da telha é repassada para a superfície interna da telha, elevando a temperatura no interior da construção.

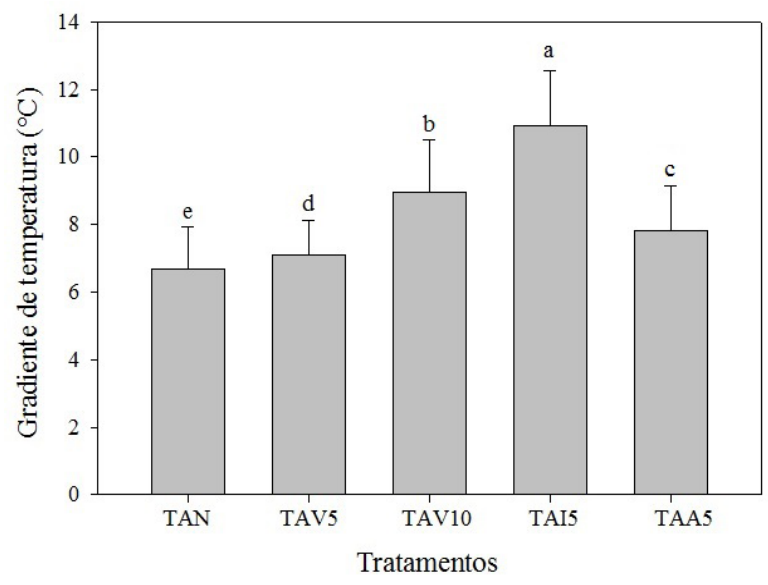

Figura 13. Valores médios e desvios-padrões do gradiente de temperatura para os diversos tratamentos testados. Médias seguidas da mesma letra, não diferem entre si pelo teste de ScottKnott, a 5\% de probabilidade.

\section{CONCLUSÕES}

- Quanto às propriedades físicas, todas as amostras de telhas de concreto com os diferentes materiais de características isolantes analisadas atenderam aos requisitos exigidos pela NBR 13.858:2 (1997).

- Para os ensaios de flexão das telhas de concreto estudadas, observou-se que a utilização dos materiais com características isolantes, influiu negativamente na resistência à flexão, sendo que a vermiculita e o aditivo incorporador de ar exerceu ao longo do período avaliado, uma maior influência.

- A incorporação de materiais com características isolantes em telhas de concreto apresentou boa eficiência, podendo apresentar melhor eficiência no conforto térmico de instalações para produção animal.

\section{AGRADECIMENTOS}

Os autores agradecem a CAPES, CNPq e FAPEMIG pelo suporte financeiro.

\section{REFERÊNCIAS BIBLIOGRÁFICAS}

ABREU, P.G.; ABREU, V.M.; COLDEBELLA, A.; LOPES, L.; CONCEIÇÃO, V.; TOMAZELLI, I. Análise termográfica da temperatura superficial de telhas. Revista Brasileira de Engenharia Agrícola e Ambiental,v.15, n.11, p.1193-1198, Campina Grande, 2011.

ARAÚJO, D.C.; MORAIS, C.R.S.; ALTIDES, M.E.D. Avaliação mecânica e físico-química entre telhas convencionais e alternativas usadas em habitações populares. Revista Eletrônica de Materiais e Processos, v.3, n. 2, p. 50-56, Campina Grande, 2008.

ASSOCIAÇÃO BRASILEIRA DE NORMAS TÉCNICAS. NBR 13858:2 - Telhas de concreto - Parte 2: Requisitos e métodos de ensaio. Rio de Janeiro: ABNT, 2009.

CONCEIÇÃO, M.N.; ALVES, S.P.; JÚNIOR, A.T.; SILVA, I.J.O.; PIEDADE, S.M.S.; JÚNIOR, H.S.; TONOLI, G. Desempenho de telhas de escória de alto forno e fibras vegetais em protótipos de galpões. Revista Brasileira de Engenharia Agrícola e Ambiental, v.12, n.5, p.536-539, Campina Grande, 2008.

FERREIRA, D.F. SISVAR - Sistema de análise estatística para dados balanceados. Lavras: UFLA/DEX, 2000. 
HANS, E.; SCHULZ, J.B. Method for producing concrete roof tiles. Patente dos EUA US5223200 A, 29 de junho de 1993.

JOHN, F.; THOMAS, S.W.F. Concrete roof tile. Patente dos EUA USD348317 S, 28 de junho de 1994.

KAWABATA, C.Y.; CASTRO, R.C.; JÚNIOR, H.S. Índices de conforto térmico e respostas fisiológicas de bezerros da raça holandesa em bezerreiros individuais com diferentes coberturas. EngenhariaAgrícola, v.25, n.3, Jaboticabal, 2005.

PARKER, D.S.; MCILVAINE, J.E.R.;BARKASZI, S.F.; BEAL, D.J.; ANELLO, M.T. Laboratory Testing of the Reflectance Properties of Roofing Material.Florida Solar Energy Center, FSECCR-670-00, Cocoa, FL, 2000.

PEIXOTO, R.A.F.; TINOCO, I.F.F.; SARAZ, J.O. ; PAULA, M.O. ; GATES, R. Elaboración y evaluación de tejas de concreto en arcilla expandida para uso como coberturas de estructuras pecuarias. Revista Facultad Nacional de Agronomia, v.65, n.2, p.5651-5660, Medellin, 2010.

SAVASTANO JUNIOR, H.; PIMENTEL, L.L. Viabilidade do aproveitamento de resíduos de fibra vegetal para fins de obtenção de material de construção. Revista Brasileira de Engenharia
Agrícola e Ambiental, Campina Grande, PB, v.4, n.1, p.103-110, 2000.

SAVASTANO JUNIOR, H.; AGOPYAN, V.; NOLASCO, A.M. ; PIMENTEL, L.L. Plant Fibre Reinforced Cement Components for Roofing. Construction \& Building Materials, , v.13, n.6, p.433-438, Oxford, UK, 1999.

SÁNCHEZDEROJAS, M.I.; MARÍN, F.P.; FRÍAS, M.; RIVERA, J. Properties and Performances of Concrete Tiles Containing Waste Fired Clay Materials. Journal of the American Ceramic Society, v.90, n.11, p.3559-3565, Westerville, Ohio, 2007.

SILVA, P.D.; SILVA, E.J. A influência de pó de brita substituindo areia e cimento na argamassa com vistas a produção de telhas. Revista Eletrônica Multidisciplinar Pindorama, Instituto Federal de Educação, Ciência e Tecnologia da Bahia - IFBA, Eunápolis, n.2, ano 3, 2012.

TÉGULA. Telhas de Concreto. Guia de Especificações. 2005.

VALCARENGHI, C.; PIOVESAN, A.Z. Análise das propriedades físicas e mecânicas nas telhas de concreto fabricadas na cidade de Herval d'Oeste. Unoesc \& Ciência - ACET, v.2, n.1, p.19-30, Joaçaba, SC, 2011. 